\author{
제주바다목장 해역 내 인공 어초군에 서식하는 \\ 어류군집의 종조성 및 계절변동 \\ 오택윤 ${ }^{*}$ - 차형기 · 장대수 · 황철희' - 남윤주' - 곽석남' 손민호' \\ 국립수산과학원 자원연구과, ${ }^{1}$ 해양생태기술연구소 어류연구팀
}

\title{
Seasonal variation and species composition of fishes communities in artificial reef unit at marine ranching area in the coastal waters off Jeju island, Korea
}

\author{
Taeg-Yun Oн*, Hyung-Kee Cha, Dae-Soo Chang, Choul-Hee Hwang ${ }^{1}$, Yun-Ju Nam ${ }^{1}$, \\ Seok-Nam KWAK ${ }^{1}$ and Min-Ho SoN ${ }^{1}$ \\ Fisheries Resources Management Division, National Fisheries Research \& Development Institute, \\ 152-1 Haeanro, Gijang, Busan 619-705, Korea \\ ${ }^{1}$ Fish Research Team, Marine Eco-Technology Institute Co., Ltd., 485-1 Yongdang, \\ Namgu, Busan 608-830, Korea
}

This study monitored a variety of marine fish communities in artificial reefs unit of the total 5 types (Dice type, Octagonal turtle type, Two-stage tube type, Gazebo type, Tetrapod type) which are located in the marine ranching at Jeju island by scuba diving in May, July, October and December 2009. Underwater photographing was accomplished at total 3 phases (condition of artificial reefs photographing, concentric circle movement photographing and line transect photographing). The preservation condition of artificial reefs facility was very good, and the dominant species were Chromis notatus, Sebastes thompsoni, Oplegnathus fasciatus and Halichoeres poecilopterus. Fish abundance was high in May and June, and low in October and December, 2009. Chromis notatus was dominant at the all types of artificial reefs, Halichoeres poecilopterus for Gazebo type and Tetrapod type of artificial reefs, and Sebastes thompsoni for Dice type, Octagonal turtle type and Two-stage tube type of artificial reefs.

Keywords: Artificial reef unit, Jeju island, Fishes communities, Marine ranching, Visual census

*Corresponding author: tyoh@nfrdi.go.kr, Tel: 82-51-720-2295, Fax: 82-51-720-2277 


\section{서 론}

우리나라 수산업은 연안 어장에 대한 의존도 가 높고, 선진국에 비해 경 영구조가 영 세하여 적 극적인 자원조성을 통한 어업관리가 필요하다. 이러한 수산 자원의 증강과 수익 증대를 위한 방 안으로 1971년부터 인공어초 시설 사업이 실시 되었으며 (Lyu and Jeong, 2000), 오늘날까지 지 속적으로 시설되 어 관리되고 있다. 특히 해양오 염, 적조그리고 지구 온난화에 의한 해양생태계 의 변화는 인공어초 시설 사업의 필요성을 극대 화 시키고 있으며, 수산자원의 부가가치 향상은 국민의 해양 레져 옥구까지 충족시킬 수 있을 것 으로 기 대하고 있다. 실제로 인공어초 어장의 수 산생물 자원 조성효과는 자연암반 어장 보다약 $1.3-2.3$ 배 정도 높은 것으로 보고되고 있는데 (Kim et al., 1999) 이는 흐름이 있는 3 차원의 빈 공간에 인공어초와 같은 인공구조물을 시설함 에 따라 저 층의 흐름을 차단 혹은 용승시켜 풍부 한 영양염류가 표층에 공급되고 이에 따라 기초 생물의 생산력이 중대되기 때문이라고 보고된 다 (Grove and Sonu, 1985). 이 와 같이 효율성 과 부가가치성이 높은 인공어초의 시설 및 관리는 연 속적으로 이루어 질 필 요가 있으며, 이에 대한 자원량 변화와 인공어초의 호과에 대한 연구도 활 발하게 이루어져야만 한다.

바다목장 해역에서의 수산자원의 분포와 밀 도를 파악하기 위한 연 구로 디지털카메 라와 과 학어군탐지기를 이용한 인공어초 주변의 어군 량 추정 연구 (Akamatsu et al., 2003; Fabi and Sala, 2002; Hwang et al., 2004), 음향텔레메 트리 기법에 의한 조피볼락(S. schlegeli) 의 인공 어초 주변에서의 행 동에 대한 연 구 (Shin et al., 2005) 등이 이루어졌으며, 수산생물의 종과 생태특성 을 파악하기 위해서는 어 구를 이용한 인 공어초 주변 어획 조사들이 일부 보고되었다 (Lee and Kang, 1994; Ahn et al., 1999; Park et al., 2000). 하 지 만 과학어군탐지기는 어초 구조물에 의한 음 향산란으로 인하여 어초 내부에 체류하는 어류
자원을 퐈악하기 어렵고, 음향텔레메트리 기법 은 어종의 행 동학적 특성 추정에 적 합한 기술로 서 인공어초주변 및 어초군 내에 자원량을 추정 에 적 용하기 어 렵다. 따라서 이 번 조사에서는 연 구자가 직 접 눈으로 인 공어초와 주변 어류상을 관찰할 수 있는 scuba diving 을 통한 수중촬영 기 법 (visual census)을 이용하여 인 공어 초 시설 상 태를 파악하고 단위어초군 내 어류자원의 현존 량을 파악하여 제 주바다목장해역에서의 단위어 초군별 서식하는 어류 분포특성을 파악하여 향 후 바다목장해역의 수산자원 조성효과를 극대 화 시키는 기초 자료를 제공하고자한다.

\section{재료 및 방법}

제주 바다목장 해역의 현장 조사는 북제주군 한경면 용수리 인근 해역의 총 5 종류의 인공어 초(사각, 팔각반구형, 원통2단형, 정자형 그리 고 대형 헥사포트)를 대상으로 2009년 5월 (춘계), 7 월( 하계), 10 월 (추계) 및 12 월 (동계) 에 어류군집 에 대하여 조사를 실시 하였 다(Fig. 1, Table 1). 각 인공어초 주변에서 출현하는 어류 종 과 현존량 을 파악하기 위하여 scuba diving 을 통한 수중비 디오 영상 촬영 (DCR - PC115, Sony) 과 수중카메 라 사진 활영 (D - 80 DSLR, Nikon)을 실시 하였 는데 작업은 총 3 단계로 이루어졌다. 첫 번째 단 계로 입수 직후 각 인공어초의 전체적인 시설 상 태와 현황을 관찰하고 기록하였으며, 두 번째 단

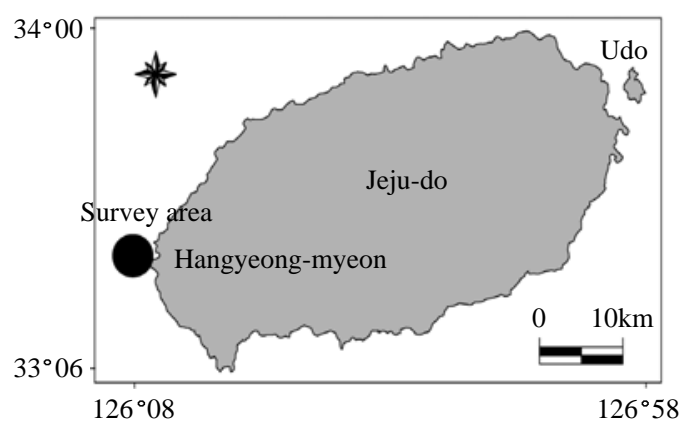

Fig. 1. Location of artificial reefs in the coastal waters off Jeju island, Korea. 
Table 1. The outline of the survey on the artificial reefs at Jeju island, Korea

\begin{tabular}{|c|c|c|c|c|}
\hline \multirow{2}{*}{ Artificial reefs } & \multirow{2}{*}{ Number } & \multirow{2}{*}{ Depth } & \multicolumn{2}{|c|}{ Location } \\
\hline & & & $\mathrm{N}$ & E \\
\hline Dice type & 200 & 40 & $33^{\circ} 19.562$ & $126^{\circ} 08.489$ \\
\hline Octagonal turtle type & 1 & 40 & $33^{\circ} 19.565$ & $126^{\circ} 08.417$ \\
\hline Two-stage tube type & 2 & 40 & $33^{\circ} 19.529$ & $126^{\circ} 08.396$ \\
\hline Gazebo type & 16 & 20 & $33^{\circ} 19.485$ & $126^{\circ} 09.140$ \\
\hline Tetrapod type & 70 & 20 & $33^{\circ} 19.523$ & $126^{\circ} 09.136$ \\
\hline
\end{tabular}

계에서는 인공어초 주변을 동심원상으로 하부 에서 상부까지 이 동하면서 촬영하였다. 마지막 으로 동 - 서, 남 - 북의 임의적 line transect를 설 정하여 왕복으로 이동하면서 촬영하였으며, 각 단계별로 특이사항은 정 확한 관찰을 위하여 이 동 속도를 늦추기도 하였다 (Fig. 2). 각 어초별 촬영시간은 40 여 분 내 외였으며, 촬영 시간 내에 출현한 어종 과 개체수는 실험실에서 동 영상을 재생하여 분석하였다. 개체수 퐈악에 있어서 한 종의 어류가 다수 출현한 경우에 는 중복으로 계 수될 우려가 있어 개체수 범위를 설정하여 결과 를 제시하였다. 또한 수중카메라 영상촬영 자료 는 수중비디오 영상촬영에서 미흡할 수 있는 부 분을비교검색할 수 있도록 이용되었으며, 출현 어종은 종 수준까지 동정하여 출현개체수를 파 악하여 우점종과 출현종을 퐈악하였다. 출현 어 종의 동정과 생태적 특성은 Masuda et al. (1984), Yoon (2002), Myung et al. (2002) 및 Kim et al. (2005)을 참고하였다.

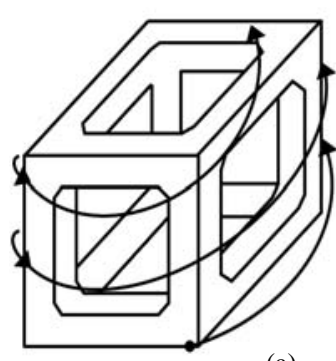

(a)

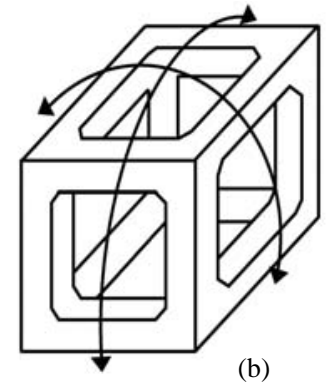

(b)
Fig. 2. The quantitative visual census method in this study (a: Concentric circle, b: All quarters transect).

\section{결 과 \\ 인공어초 시설 및 보존상태}

인공어초 시설의 보존 상태는 매우 양호하였 다. 인공어초 투입시에 흔히 발생 할 수 있는 모 서리 부분의 훼손이 일부 관찰되었으나 어초군 형 성에 큰 영향을 미 칠 정 도는 아닌 것으로 퐌단 되었다. 또한해 저 기 질에 따라 니질의 상태에서 는 어초하단부 일부가 매몰되어 있기도 하였으 나, 전체적으로는 극히 일부를 제외하고는 대부 부의 인공어초들이 기능을 유지하는데 양호하 였다. 또한 인공어초에 부착하여 서식하는 무척 추 동물과 해조류들도 다량관찰되 었다(Fig. 3).

\section{어초군별 출현양상}

사각어초에서 출현한 어류는 총 11 종으로 이 중에서 자리돔 (Chromis notatus) 과 불볼락 (Sebastes thompsoni)이 우점하였으며, 이들은 인 공어초 내에서 무리지어 서식하고 있었다. 자리 돔(C. notatus)은 4회 조사 모두 출현 한 반면 불볼 락 (S. thompsoni)이 3 회만 출현 하였 고, 나머지 대 부분의 어류들이 1 -2회 출현하였다. 팔각반구 형 강제어초에서는 총 12 종의 어류가 출현하였 으며, 사각어초와 마찬가지 로 자리돔 (C. notatus) 과 불볼락 (S. thompsoni)이 우점하였다. 우점종과 더불어 불볼릭(S. thompsoni) 과 쥐치 (Stephanolepis cirrhifer)이 4회 출현하였으며, 돌 돔 (Oplegnathus fasciatus) 은 3 회, 용치 놀래기 (Halichoeres poecilopterus) 등 나머지 어류들은 $1-2$ 회 출현하였다. 원 통 2 단형강제 어초에서는 

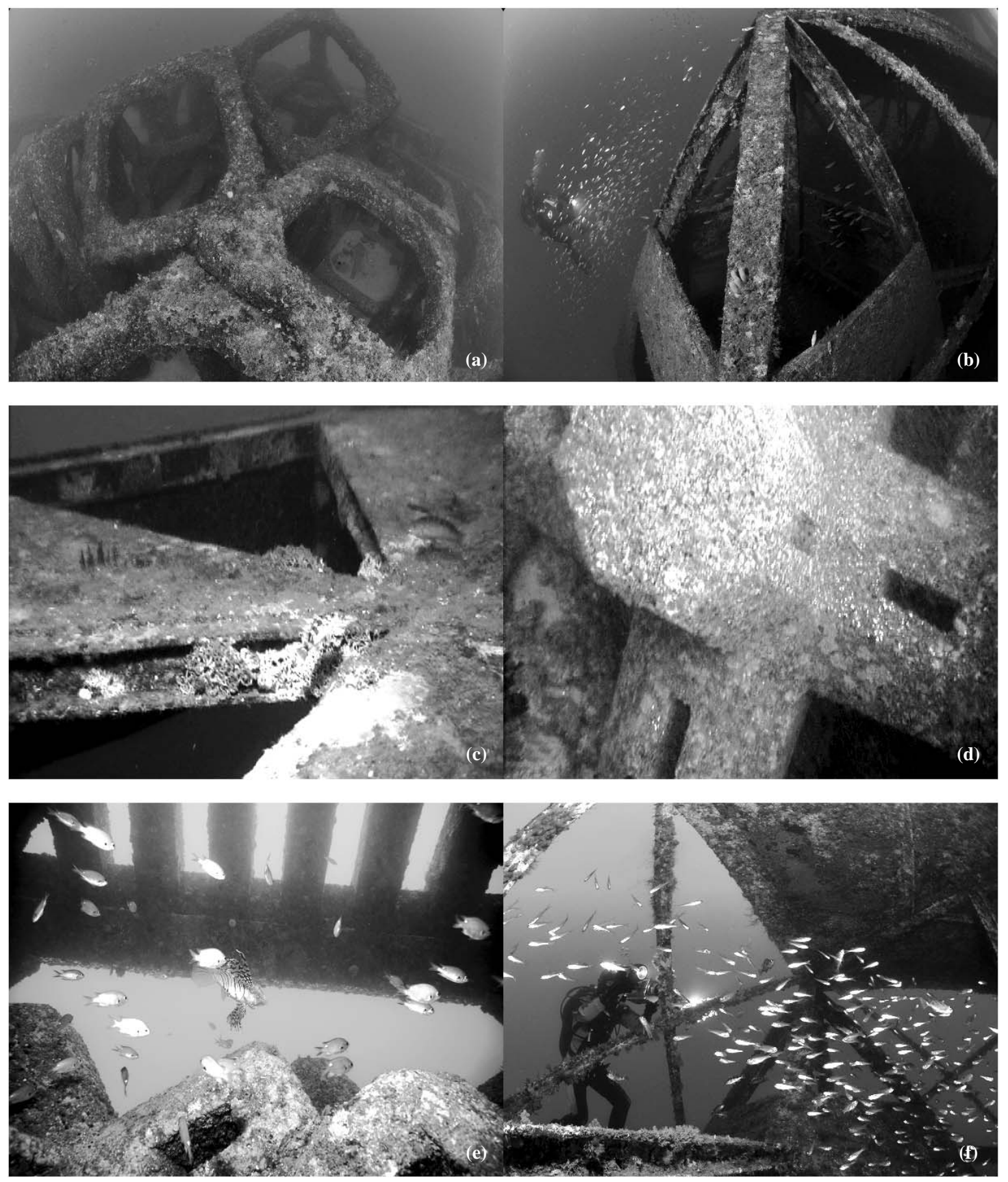

Fig. 3. The scenes of underwater photographing and the status of the artificial reefs in the study area (a: Dice type, b: Octagonal turtle type, c: Two-stage tube type, d:Tetrapod type, e: Gazebo type and f: Underwater photographing).

총 13 종의 어류가 출현하였으며, 불볼락 $(S$. thompsoni)과 자리돔 (C. notatus)이 우점하였다. 자리돔 (C. notatus)은 출현개체수가 가장 많았지
만, 7 월 조사에서는 출현하지 않았고, 쥐치 (S. cirrhifer)는 출현개체수가 적었으나 4 회 출현하 였다. 돌돔(O. fasciatus) 등 나머지 어류들은 1 - 
Table 2. Monthly variation of fish numbers at each artificial reefs in the study area

(++++, Upper 1,000; +++, 100 - 1,000; ++, 10 -100; +, Below 10 individuals)

\begin{tabular}{|c|c|c|c|c|c|c|c|c|c|c|c|c|c|c|c|c|c|c|c|c|}
\hline \multirow[t]{2}{*}{ Species } & \multicolumn{4}{|c|}{ Dice type } & \multicolumn{4}{|c|}{$\begin{array}{l}\text { Octagonal turtle } \\
\text { type }\end{array}$} & \multicolumn{4}{|c|}{$\begin{array}{c}\text { Two-stage tube } \\
\text { type }\end{array}$} & \multicolumn{4}{|c|}{ Gazebo type } & \multicolumn{4}{|c|}{ Tetrapod type } \\
\hline & May & Jul. & Oct. & Dec. & May & Jul. & Oct. & Dec. & May & Jul. & Oct. & Dec. & May & Jul. & Oct. & Dec. & May & Jul. & Oct. & Dec. \\
\hline \multicolumn{21}{|l|}{ Order Zeiformes } \\
\hline \multicolumn{21}{|l|}{ Family Zeidae } \\
\hline Zeus faber & + & & & & + & & & & & & & & & & & & & & & \\
\hline \multicolumn{21}{|l|}{ Order Scorpaeniformes } \\
\hline \multicolumn{21}{|l|}{ Family Scorpaenidae } \\
\hline Pterois lunulata & & & & & & & & & & & & & + & + & + & & + & + & & \\
\hline Sebastes schlegeli & & & & & & & & & & & & & & & & & & & & + \\
\hline Sebastes thompsoni & & ++++ & +++ & +++ & ++ & +++ & +++ & +++ & + & +++ & +++ & +++ & & & & & & & & \\
\hline Sebastiscus marmoratus & & & & & & & & & & & & & & & + & + & & & & \\
\hline \multicolumn{21}{|l|}{ Family Hexagrammidae } \\
\hline Hexagrammos otakii & & & & & & & & & & & & & & & & & + & & & \\
\hline Order Perciformes & & & & & & & & & & & & & & & & & & & & \\
\hline Family Serranidae & & & & & & & & & & & & & & & & & & & & \\
\hline Epinephelus akaara & & & & & & & & & ++ & & & & & & & & & & & \\
\hline Epinephelus septemfasciatus & & & & & & & & & & & & & + & & & & + & & & \\
\hline Family Apogonidae & & & & & & & & & & & & & & & & & & & & \\
\hline Apogon semilineatus & +++ & & & & & +++ & & & & & & + & ++ & & & & & & & \\
\hline Family Sillaginidae & & & & & & & & & & & & & & & & & & & & \\
\hline Sillago aeolus & & & & & & & & & & & & & & & ++ & & & & + & \\
\hline Family Carangidae & & & & & & & & & & & & & & & & & & & & \\
\hline Trachurus japonicus & & ++ & ++ & & & & & & & & & & & & & & & & ++ & \\
\hline Family Caesionidae & & & & & & & & & & & & & & & & & & & & \\
\hline Pterocaesio trilineata & & & & & & & & & ++ & & & & & & & & & & & \\
\hline Family Pomacanthidae & & & & & & & & & & & & & & & & & & & & \\
\hline Chaetodontoplus septentrionalis & & & & + & & & & & & & & & & & & & & & & \\
\hline Family Kyphosidae & & & & & & & & & & & & & & & & & & & & \\
\hline Girella punctata & & & & & & & & & & & & & & & & & + & & & \\
\hline Microcanthus strigatus & + & & & & & & + & & & & ++ & ++ & & & & ++ & + & & ++ & \\
\hline Rhyncopelates oxyrhynchus & + & & & & + & ++ & & & & & & & & & & & + & & & \\
\hline Terapon jarbua & & & & & & & & & & & & & & & & & & & ++ & \\
\hline Family Oplegnathidae & & & & & & & & & & & & & & & & & & & & \\
\hline Oplegnathus fasciatus & ++ & + & & + & ++ & ++ & + & & ++ & ++ & & & & & & + & + & & ++ & + \\
\hline Family Cheilodactylidae & & & & & & & & & & & & & & & & & & & & \\
\hline Goniistius zonatus & & & & & + & + & & & + & & & & + & & + & & + & + & & + \\
\hline Family Pomacentridae & & & & & & & & & & & & & & & & & & & & \\
\hline Chromis notatus & ++++ & ++++ & +++ & ++ & ++++ & +++ & +++ & + & +++ & & ++ & ++ & ++ & +++ & ++ & +++ & +++ & +++ & ++ & +++ \\
\hline Family Labridae & & & & & & & & & & & & & & & & & & & & \\
\hline Choerodon azurio & & & & & & & & & & & & & + & & & + & & & & \\
\hline Halichoeres poecilopterus & & + & & & & + & + & & & & & & ++ & + & ++ & ++ & + & ++ & ++ & + \\
\hline Pseudolabrus japonicus & & & & & & & + & & & + & & & + & & & & + & + & + & + \\
\hline Semicossyphus reticulatus & & & & & & & & & & & & & + & & & & & & & \\
\hline Family Pinguipedidae & & & & & & & & & & & & & & & & & & & & \\
\hline Parapercis sexfasciatus & & & & & & & & & & & & & & & & & & ++ & & \\
\hline Family Blenniidae & & & & & & & & & & & & & & & & & & & & \\
\hline Petroscirtes breviceps & & & & & & & & & & & & & + & & + & & + & & & \\
\hline Family Gobiidae & & & & & & & & & & & & & & & & & & & & \\
\hline Sagamia geneionema & & & & & & & & & & & & & + & & & & & & & \\
\hline Tridentiger trigonocephalus & & & & & & & & & & + & & & & & + & & & & & \\
\hline Order Tetraodontiformes & & & & & & & & & & & & & & & & & & & & \\
\hline Family Monacanthidae & & & & & & & & & & & & & & & & & & & & \\
\hline Stephanolepis cirrhifer & + & & & & + & + & + & + & + & + & + & + & + & & + & + & + & + & & \\
\hline Thamnaconus modestus & + & & & & & + & & & + & & & & + & & & + & & & & \\
\hline Number of species & 8 & 5 & 3 & 4 & 7 & 9 & 7 & 4 & 8 & 5 & 5 & 4 & 13 & 3 & 9 & 8 & 13 & 7 & 8 & 6 \\
\hline
\end{tabular}


2 회 출현하였다. 정자형어초에서는 총 18 종의 어류가 출현하여 자리돔(C. notatus)과 용치놀래 기 (H. poecilopterus) 가 4회 출현하면서 우점 하 었고, 쥐치 (S. cirrhifer)는 3 회, 그 밖의 다른 어 류들은 1-2회 출현하였다. 대형헥사포트어초 는 정자형어초의 어류 출현양상과 유사하였다. 총 18 종의 어류가 출현하여 자리돔 (C. notatus) 과 용치놀래기 (H. poecilopterus)가 우점하였으 며, 이들 우점종들과 황놀래기 (Pseudolabrus japonicus) 가4회, 돌돔(O. fasciatus)과 아홉동가 리 (Goniistius zonatus)가 3 회, 그 이외 대부분의 어류들은 1-2회 출현하였다(Table 2).

\section{계절별 출현양상}

사각어초에서 출현한 어류의 개체수는 7 월 에 가장 많았으며, 12 월에 가장 적었다. 우점종인 자리돔 (C. notatus) 과 불볼락 (S. thompsoni)이 7 월에 출현량이 가장 많은 반면에 2 월에는 매우 적 게 출현하여 전체 출현양상에 큰 영향을 미친 것으로 판단되며, 다른 대부분의 어류들은 계절 에 상관없이 10 개체 이하로 출현하였다. 줄도화 돔 (Apogon semilineatus)은 5월 조사에서만 200 여 개체가 무리지어 서식하고 있었으며, 전 갱이 (Trachurus japonicus)는 10 월 조사에서 어초의 상부에 무리지어 서식하고 있었다. 팔각반구형 강제어초에서의 출현한 어류의 개체수는 7 월 에 가장 많았고, 12 월 에 가장 적었다. 5 월 과 7 월 의 전체 어류 출현량은 유사하였으나5월 에는 자리 돔 (C. notatus) 1 종이 무리지 어 출현한 반면, 7 월 에는 자리돔 (C. notatus)을 비롯하여 불볼락 ( $S$. thompsoni) 과 줄도화돔 (A. semilineatus)이 무리 지어 출현하였다. 또한 돌돔 (O. fasciatus)과 줄 벤자리 (Rhyncopelates oxyrhynchus) 가 10 개체 이 상 출현하였으며, 대부분 의 어류들은 10 개체 이 하로 출현하였다. 원 통 2 단형강제어초에서는 5 월 에 출현한 어류의 개체수가가장 많았으며, 12 월 조사에서 가장적게 출현하였다. 이는 자리돔 (C. notatus)이 5월에 대 량으로 무리지 어 출현한
반면 다른 시기에 는 출현하지 않았기 때 문이다. 또한 불볼락 (S. thompsoni)은 5 월 에 10 개 체 이 하 로 출현한 반면 다른 시기에는 100 개체 이 상 출 현 하었고, 그 외 붉바리 (Epinephelus akaara), 세 줄 가 는 돔 (Pterocaesio trilineata), 범 돔 (Microcanthus strigatus), 돌돔(O. fasciatus) 그리 고 자리돔 (C. notatus)이 10 개체 이상 출현하였 다. 정자형 어초에서는 7 월 에 가장 많은 어류의 개체수가 출현하였으며 10 월에 가장 적었다. 하 지 만어류가 가장많이 출현한 7 월에는 단 3 종만 이 출현하여 가장적은 출현종수를 보였다. 이는 우점종인 자리돔 (C. notatus)이 7 월 에 대 량으로 출현하었기 때문이며, 전체적으로는 자리돔 (C. notatus) 외에도 용치놀래기 (H. poecilopterus), 줄도화돔 (A. semilineatus), 별보리멸 (Sillago aeolus) 그리고 범돔 (Microcanthus strigatus)이 10 개체 이상출현하였고, 그 외 어종들은 10 개체 이하로 출현하였다. 대형헥사포트어초는 5 월 에 가장 많은 어류의 개체수가 출현하였으며, 12 월 에 가장 적었다. 자리돔 (C. notatus)은 100 개체 이상이 무리지어 서식하고 있었으며, 용치놀래 기 (H. poecilopterus), 전 갱이 (T. japonicus) 그리 고 돌돔 (O. fasciatus) 등이 10 개체 이상 출현하 였다. 각 어초군에서의 계절별 출현양상은 5 월 과 7 월 에 많은 어류들이 출현하였으며, 10 월 과 12 월 에 대체로 적 은 어류가 출현하였다. 또한 출

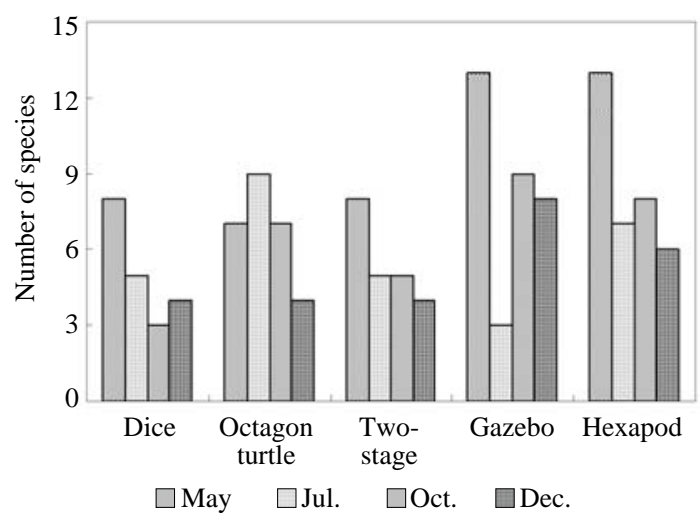

Fig. 4. Difference of number of fish species at each artificial reefs in the study area. 


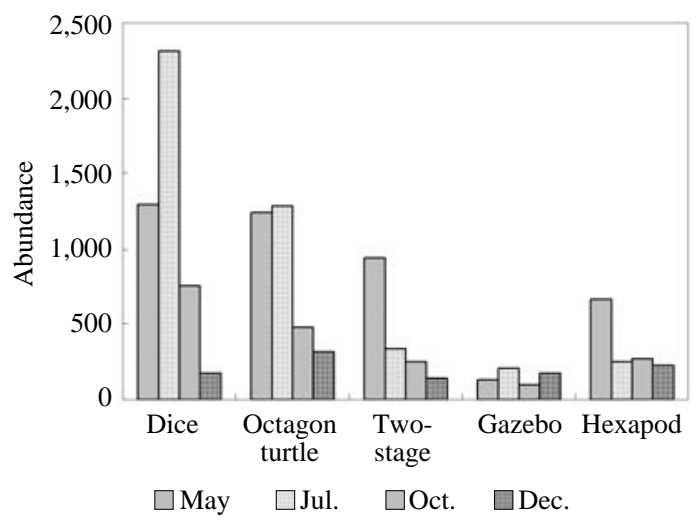

Fig. 5. Difference of abundance of fish species at each artificial reefs in the study area

현 종수는 팔각반구형강제어 초를 제 외하고는 5 월에 가장 많은 특징을 보였다. 어초별 출현 종 수는 정자형과 대형헥사포트어초에서 다소 많 이 출현하였으며, 출현개체수는 사각어초와 팔 각반구형어 초에서 많았다 (Fig 4, 5).

\section{고 찰}

Ahn et al. (1999) 은 제 주도 연 안 인 공어초의 집 어효과에 대해 보고하였는데, 본 조사와는 출현 종에 있어서 다소 차이를 보였다. 이는 제주도 북부해역과 서부해역의 조사지점 차이에 따른 것으로 이는 어류의 이 동과 관련한 해 류의 영 향 이 큰 것으로 생각된 다. Park et al. (2000)은 전라 북도 연 안 인공어초를 대 상으로 시설 상태와 수 중촬영을 통한 어류의 출현양상을 보고하였다. 총 21 종의 어류와 기타 무척추동물 및 부착생물 을 보고하였는데, 우리나라 연 안에서 흔히 관찰 할 수 있는 쥐노래미 (Hexagrammos otakii), 조피 볼락 (Sebastes schlegeli), 넙치 (Paralichthys olivaceus) 등이 관찰되 었으며, 어획호과를 파악 하기 위한 어구별 단위노력당 어획량은 인공어 초 시설구에서 의 어 획효과가 비교구보다 2 배 정 도 높았다. 이렇듯 인 공어초 시설에 대해 긍적적 인 경제적 파급호과는 분명할 겻으로 생각되지 만 정 확한 자원량 산출을 위한 연속적 인 조사가 실시되 어야할 것으로 생 각된 다.
인공어초는 수산생물을 모이게 하는 역할 뿐 만 아니라 기초생물의 증식 효과를 유발하여 먹 이사슬의 안정화를 가져와 유용수산 자원의 생 산력 증진과 산란 - 성육장을 제 공한다. 뿐만 아 니라 연안의 불법어업을 막는 역할을 담당하여 수산자원의 보호, 육성을 증진 시킬 수 있다 (Okamoto et al., 1979; Kawasaki, 1984; Buckley and Hueckel, 1985; Lee and Kang, 1994; Park et al., 2000). 인 공어초에 의 한 효과는 크게 4 가지 로 볼 수 있다 첫 번째가 어장가치가 낮은 천해 수역을 양호한 어장으로 개조하는 것, 두 번째가 새로운 어장 조성, 세 번째가 집어시설, 마지막 으로 종모 보호 육성장으로 이용하는 것이다. 이 번 조사에서의 인 공어 초는 비교적 깊은 수심이 었으나 상업성을 가지는 크기의 어류 군집들이 무리지어 서식하여 유용 어장과 집어 기 능을 수 행 하고 있었으며, 미 동정 자치어들이 대 량으로 서식하고 있었으므로 보호 육성장으로서의 기 능도 수행하고 있었다.

어류들은 각각의 먹이 습성과 행 동 양상이 다 르기 때문에 인 공어초의 종류에 따라 군집 양상 이 다를 수 있다. 따라서 시설 장소의 특성이나 대상어종에 따라 인공어초의 모형이나 종류에 차이를 두어야 한다고 보고되었다 (Matthews, 1985; Nakamura, 1985). Choi et al. (2000)은 어초 별 어류의 출현개체수가 콘크리트 재질로 만들 어진 인 공어 초보다는 넓 은 내 부공간을 제 공 할 수 있고, 지붕 (roof)에 의해 발생되는 그늘 호과 (shadow effect) 를 제 공할 수 있는 강제어초에서 더욱 많은 어류들이 출현한다고 보고하였다. 본 조사에서도 인공 어초의 종류와 조사시기에 따 라 출현양상이 다소 차이를 보였다. 사각어초와 비교해서 강제어초에서의 어류 출현량이 많았 으며, 대형헥사포트어초는 구조가 강제어초와 차이를 보이지만 어초 구조상 지그재그형으로 겹쳐지 며 그늘 또는 은닉 장소를 제 공하였고, 좁 은 지역에 표면적을 넓힐 수 있는 장점으로 어류 출현량이 많있던 것으로 보인다. 하지만 이번 조 
사에서 이용된 각각의 인공어초에서의 차이는 전체적으로 뚜렷하지 않았으며 이는 인공 어초 간의 지역적인 거리 차이가 적어서 우점종이 유 사하였기 때문으로도 생각된다. 우점종인 자리 돔 (C. notatus)은 수심 $20-30 \mathrm{~m}$ 의 산호초나 암 반 지역에 무리지어 서식하는 종으로 우리나라 의 제주도를 포함하는남해에 주로 서식하며, 해 수온의 상승에 따라 오늘날에는 동해안까지 널 리 분포하고 있다. 또한 불볼락(S. thompsoni)은 수심이 다소 깊은 $30-150 \mathrm{~m}$ 의 암초지역에 무리 지어 서식하는 종으로 우리나라의 남해안에 주 로 분포하며, 돌돔은 비교적 따뜻한 수온의 연안 바위지역에서 서식하며 바다낚시와 양식대상종 으로 인기가 있다 (Yoon, 2002; Myung et al., 2002; Kim et al., 2005).

본 조사에서 이용된 scuba diving 을 통한 수중 촬영 기법 (visual census)은 연 안성 어류와 같은 수산생물의 양을 측정하기 위해 일 반적으로 널 리 사용되는 방법 중의 하나이다 (Chabanet et al., 1995; Edgar and Barrett, 1997; De Girolama and Mazzoldi, 2001; Pet - Soede et al., 2001; Guidetti et al., 2002). 이전의 방법들은 바다목장 해역에서의 수산자원의 분포와 밀도를 파악하 는데 중요한 기술로 활용될 수 있는 반면 수산생 물의 종과 생태특성을 파악하는데 어려움이 있 다. 따라서 scuba diving 을 통한 수산자원의 직 접적인 관찰과 채집, 그리고 어군탐지기를 이용 한 조사가 병행된 다면 보다 정 확한 자로를 얻을 수 있을 것으로 생각되 며, 앞으로도 인공어초시 설어장에서의 어군 행동과 해양환경에 미치는 영향, 그리고 인 공어초 시설규모의 적 절성 에 대 한 많은 연 구가 필요할 것이다.

\section{결 론}

제 주 바다목장해 역 내 에 시설한 5 종류 인 공어 초 (사각, 팔각반구형, 원 통2 단형, 정자형 및 대 형헥사포트)의 단위어초군별로 서식하는 어류 분포특성을 퐈악하여 향후 바다목장 조성해역
조성시 수산자원 조성효과를 극대화시키기 위 한 어류의분포 특성을 파악하였다. 그 결 과, 제 주 바다목장해역의 우점종은 자리돔 (C. notatus), 불볼 락 (S. thompsoni), 돌 돔 (O. fasciatus) 그리고 용치놀래기 (H. poecilopterus) 이다. 또한 계절별 출현양상은 5 월 과 7 월에 많 은 어 류들이 출현하였으며, 10 월 과 12 월 에 대 체 로 적은 어류가 출현하였다. 어초종류별 출현 종수는 정자형과 대형헥사포트어초에서 다소 많이 출현하였으며, 출현개체수는 사각어초와 팔각반구형어초에서 많았다. 자리돔(C. notatus) 은 인공어초종류에 구분없이 다른 어종보다 우 점하게 분포하였고, 정자형과 대형헥사포트어 초에서는 용치놀래기 (H. poecilopterus) 가 우점 하고, 사각과 팔각반구형 및 원 통2단형어초에서 는 불볼락 (S. thompsoni), 이 우점한 것으로 나타 났다:

\section{사 사}

본 연구는 2009년 국립수산과학원 바다목장 사업 수산자원조사평가분야 (RP - 2010 - FR 011)의 지원에 의해 수행되었습니다.

\section{참고문헌}

Ahn, Y.W., H.K. Rho, S.J. Kim, D.G. Jeung and M.K. Kim, 1999. Studies on the improvement of the fish gathering effects of artificial fish reefs in the coastal area of Cheju Island. J. Fish. Mar. Sci. Edu., 11 (1), $59-68$.

Akamatsu, T., H. Takahashi and A. Matsuda, 2003. A monitoring system for the aggregated fish group by an acoustic - visual combined method. Scientist, 4, $18-26$.

Buckley, R.M. and G.J. Hueckel, 1985. Biological processes and ecological development on an artificial reef in Puget Sound, Washington. Bull. Mar. Sci., 37 (1), 50 - 69.

Choi, C.G., 2008. Marine communities around artificial reefs located in Ikata, Shikoku, Japan. J. Kor. Fish. 
Soc., 41 (3), 208 - 214.

Chabanet, P., V. Dufour and R. Galzin, 1995. Disturbance impact on reef fish communities in Reunion Island (Indian Ocean). J. Exp. Mar. Biol. Ecol., 188, 29 - 48.

De Girolama, M. and C. Mazzoldi, 2001. The application of visual census on Mediterranean rocky habitats. Mar. Environ. Res., 51, 1 - 16.

Edgar, G.J. and N.S. Barrett, 1997. Short term monitoring of biotic change in Tamanian marine reserves. J. Exp. Mar. Biol. Ecol., 213, 261 - 279.

Fabi, G. and A. Sala, 2002. An assessment of biomass and diel activity of fish at an artificial reef (Adriatic sea) using a stationary hydroacoustic technique. ICES J. Mar. Sci., 59, 411 - 420.

Grove, R.S. and C.J. Sonu, 1985. Fishing reef planning in Japan. Artificial Reefs: Marine and Freshwater Applications. D'Itri, F.M., ed. Lewis Publication. Inc., Michigan, USA, pp. 187 - 251.

Guidetti, P., G. Fanelli, S. Fraschetti, A. Terlizzi and F. Boero, 2002. Coastal fish indicate human - induced changes in the Mediterranean littoral. Mar. Environ. Res., 53, 77 - 94.

Hwang, D.J., J.S. Park and Y.W. Lee, 2004. Estimation of fish school abundance by using an echo sounder in an artificial reef area. J. Kor. Fish. Soc., 37 (3), $249-254$

Kawasaki, T., 1984. The distribution and behavior of fishes in the artificial reef fishing grounds. In Biological Process in the Ocean, R. Marushige, ed. Koseisha Koseikaku, Tokyo, pp 197 - 200.

Kim, H.S., H.S. Lim, Y.J. Jo, J.I. Choi and O.I. Choi, 1999. Benthic macrofauna on the artificial reefs and their surrounding bottom in the southwest coast of Korea. Bull. Nat. Fish. Res. Dev. Inst., Korea, 56, $13-26$.

Kim, I.S., Y. Choi, C.L., Lee, Y.J. Lee, B.J. Kim and J.H. Kim, 2005. Illustrated book of korean fishes. KyoHak Sa, Seoul. pp. 615
Lee, J.W. and Y.S. Lee, 1994. Variations of fish community and fish density on artificial reefs. J. Kor. Fish. Soc., 27 (5), 535 - 548.

Lyu, J.G. and M.S. Jeong, 2000. A Study on the economic appraisals of artificial reefs. Ocean Policy Research, 15, pp. 27.

Masuda, H., K. Amaoka, C. Arago, T. Ueno and T. Yoshino, 1984. The Fishes of the Japanese Archipelago, Tokai University, Press, Tokyo, Japan, pp. 437.

Matthews, K.R. 1985. Species similarity and movement of fishes on natural and artificial reefs in Monterey Bay, California. Bull. Mar. Sci., 37 (1), 252 - 270.

Nakamura, M. 1985. Evolution of artificial fishing reef concepts in Japan. Bull. Mar. Sci, 37 (1), 271 - 278.

Myung, J.G., B. I. Kim, S.M. Lee and G.B. Jeon, 2002. The sea fishes of Korea. Darakwon, Seoul, pp. 287.

Okamoto, M., T. Kuroki and T. Muriai, 1979. Fundamental studies on the ecology of fishes near artificial reefs. 1. Preparatory observation of fish amount. Bull. Jap. Soc. Sci. Fish., 45 (9), 1085 1090.

Park, J.S., M.S. Seo and J.H. Kim, 2000. Effect of artificial fish reefs in the costal area of Jeon Bug province. J. Fish. Mar. Sci. Edu., 12 (1), 11 - 21.

Pet - Soede, C., W.L.T. van Densen, J.S. Pet and M.A.M. Machiels, 2001. Impact of Indonesian coral reef fisheries on fish community structure and the resultant catch composition. Fish. Res., 51, 35 - 51.

Shin, H.O., J.W. Tae and K.M. Kang, 2005. Acoustic telemetrical measurement of the movement range and diurnal behavior of rockfish (Sebastes schlegeli) at the artificial reef. J. Kor. Fish. Soc., 38 (2), 129 136.

Yoon, C.H., 2002. Fishes of Korea with pictorial key and systematic list. Academybook, Seoul. pp. 747.

2010년 2 월 24일 접 수

2010년 4 월 5 일 1 차 수정

2010 년 5 월 3 일 2 차 수정

2010년 5월 7일 수리 